\title{
RADIUS, DIAMETER, MULTIPLISITAS SIKEL, DAN DIMENSI METRIK GRAF KOMUTING DARI GRUP DIHEDRAL
}

\author{
Abdussakir \\ UIN Maulana Malik Ibrahim Malang, sakir@mat.uin-malang.ac.id
}

\begin{abstract}
Abstrak
Graf komuting $C(G)$ dari suatu grup non Abelian $G$ adalah graf yang memuat semua anggota grup $G$ sebagai himpunan titik dan dua titik akan terhubung langsung di $C(G)$ jika keduanya komutatif di grup $G$. Dalam artikel ini dibahas mengenai graf komuting dari grup dihedral $D_{2 n}$. Pembahasan dibatasi pada topik radius, diameter, multiplisitas sikel, dan dimensi metrik. Beberapa teorema disajikan terkait topik tersebut disertai bukti kebenarannya.
\end{abstract}

Kata kunci: radius, diameter, multiplisitas sikel, dimensi metrik, graf komuting, grup dihedral.

\begin{abstract}
Commuting graph $C(G)$ of a non Abelian group $G$ is graph that contains all element of $G$ as its vertex set and two distinct vertices in $C(G)$ will be adjacent if they are commute in $G$. In this paper we discuss about commuting graph of dihedral group $D_{2 n}$. We show radius, diameter, cycle multiplicity, and metric dimension of this commuting graph in several theorems with their proof.
\end{abstract}

Keywords: radius, diameter, cylce multiplicity, metric dimension, commuting graph, dihedral group.

\section{Pendahuluan}

Graf $G$ memuat $V(G)$ sebagai himpunan tidak kosong dan berhingga dari objek-objek yang disebut titik dan $E(G)$ sebagai himpunan pasangan tak berurutan dari titik-titik berbeda di $V(G)$ yang disebut sisi. $E(G)$ dapat berupa himpunan kosong [1]. Jika $e=(u, v)$ adalah sisi di graf $G$, maka $u$ dan $v$ disebut terhubung langsung. Kardinalitas $V(G)$ disebut order dari $G$ dan kardinalitas dari $E(G)$ disebut ukuran dari $G$ [2].

Perkembangan terbaru teori graf juga membahas graf yang dibangun dari grup. Misal $G$ grup berhingga tak komutatif dan $X$ adalah subset dari $G$. Graf komuting $C(G, X)$ adalah graf yang memiliki himpunan titik $X$ dan dua titik berbeda akan terhubung langsung jika saling komutatif di $G$. Jadi, titik $x$ dan $y$ akan terhubung langsung di $C(G, X)$ jika dan hanya jika $x y=$ $y x \operatorname{di} G$ [3].

Beberapa penelitian mengenai graf komuting telah dilakukan. Vahidi \& Talebi [3] meneliti bilangan bebas, bilangan clique, dan bilangan cover minimum graf komuting grup $D_{2 n}$ dan $Q_{n}$. Chelvam, dkk [4] meneliti beberapa sifat pada graf komuting dari grup dihedral dan menemukan bahwa bilangan kromatik pewarnaan titik sama dengan bilangan clique pada graf komuting yang diperoleh dari grup dihedral. Rahayuningtyas, dkk [5] meneliti bilangan kromatik perwarnaan titik dan 
pewarnaan sisi pada graf komuting dan non komuting dari grup dihedral.

Pada penelitian ini dikaji beberapa sifat pada graf komuting dari grup dihedral untuk topik yang belum dibahas pada penelitianpenelitian sebelumnya. Kajian difokuskan pada topik radius, diameter, multiplisitas sikel, dan dimensi metrik.

\section{Kajian Teori}

\subsection{Radius dan Diameter Graf}

Misalkan $G$ graf terhubung. jarak antara titik $u$ dan $v$ di $G$, dinotasikan dengan $d(u, v)$, adalah panjang lintasan terpendek yang menghubungkan $u$ dan $v$ di $G$. Eksentrisitas titik $v$ di $G$, dinotasikan dengan $e(v)$, adalah jarak terjauh dari titik $v$ ke semua titik di $G$. Jadi dapat dituliskan $e(v)=\max \{d(u, v) \mid u \in V(G)\}$. Titik $v$ dikatakan titik eksentrik dari $u$ jika jarak dari $u$ ke $v$ sama dengan eksentrisitas dari $u$ atau $d(u, v)$ $=e(u)$. Radius dari $G$, dinotasikan dengan $\operatorname{rad}(G)$, adalah eksentrisitas minimum dari semua titik di G. Jadi, dapat dituliskan $\operatorname{rad}(G)=$ $\min \{e(v) \mid v \in V\}$. Sedangkan diameter dari $G$, dinotasikan dengan $\operatorname{diam}(G)$, adalah eksentrisitas maksimum dari semua titik di $G$. Jadi, dapat dituliskan $\operatorname{diam}(G)=\max \{e(v) \mid v \in V\}[6][2]$.

\subsection{Multiplisitas Sikel}

Dua sikel atau lebih di dalam suatu graf disebut saling lepas sisi jika sikel- sikel tersebut tidak memuat sisi yang sama. Multiplisitas sikel dari graf $G$, dinotasikan dengan $\operatorname{cm}(G)$, didefinisikan sebagai bilangan terbesar yang menyatakan banyaknya sikel yang saling lepas sisi yang terdapat dalam graf $G$ [7].

\subsection{Dimensi Metrik}

Misalkan $G$ graf, $S=\left\{\begin{array}{llll}x_{1}, & x_{2}, \ldots, x_{n}\end{array}\right\}$ himpunan bagian dari $V(G)$, dan $v$ adalah titik di $G$. Representasi dari $v$ terhadap $S$ adalah tuple-n berurutan, $r(u \mid \mathrm{S})=\left(d\left(v, x_{1}\right), d\left(v, x_{2}\right), \ldots, d\left(v, x_{n}\right)\right)$, dengan $d\left(v, x_{i}\right)$ adalah jarak antara titik $v$ dan titik $x_{i}$. Himpunan $S$ merupakan himpunan pemisah pada graf $G$ jika untuk setiap titik pada graf $G$ mempunyai representasi jarak yang berbeda terhadap $S$. Himpunan pemisah dengan banyak anggota minimum dinamakan basis dari graf $G$. Dimensi metrik pada graf $G$ adalah kardinalitas minimum pada himpunan pemisah, dan dilambangkan dengan $\operatorname{dim}(G)$. Dengan kata lain, $\operatorname{dim}(G)$ adalah kardinalitas basis dari graf $G$ [8].

\subsection{Grup Dihedral}

Grup dihedral adalah grup dari himpunan simetri-simetri dari segi- $n$ beraturan, dinotasikan dengan $D_{2 n}$, untuk setiap $n$ bilangan bulat positif dan $n \geq 3$. Grup dihedral $D_{2 n}$ dapat dinyatakan sebagai

$$
D_{2 n}=\left\{1, r, r^{2}, \ldots, r^{n-1}, s, s r, s r^{2}, \ldots, s r^{n-1}\right\} .
$$

\subsection{Graf Komuting}

Misal $G$ adalah grup berhingga tak komutatif dan $X$ adalah subset dari $G$. Graf komuting $C(G, X)$ adalah graf dengan $X$ sebagai himpunan titik dan dua elemen berbeda di $C(G, X)$ akan terhubung langsung jika keduanya adalah elemen yang saling komutatif di $G$ [3]. Dalam hal $X=G$, maka $C(G, X)$ akan ditulis $C(G)$

\section{Hasil Penelitian}

\section{Teorema 1.}

Misalkan $D_{2 n}=\left\{1, r, r^{2}, \ldots, r^{n-1}, s, s r, s r^{2}, \ldots\right.$, $\left.s r^{n-1}\right\}$ adalah grup dihedral order $n$ dengan $n$ bilangan bulat dan $n \geq 3$.

a. Jika

$$
X=\left\{1, r, r^{2}, \ldots, r^{n-1}\right\} \subseteq D_{2 n}
$$

maka graf komuting $C(D, X)$ akan membentuk graf komplit order $n$, yaitu $K_{n}$.

b. Jika

$$
X=\left\{1, s, s r, s r^{2}, \ldots, s r^{n-1}\right\} \subseteq D_{2 n},
$$

untuk $n$ ganjil, maka graf komuting $C(D, X)$ akan membentuk graf bintang order $(n+1)$, yaitu $S_{n}$.

c. Jika

$$
X=\left\{1, r^{\frac{n}{2}}, s, s r, s r^{2}, \ldots, s r^{n-1}\right\} \subseteq D_{2 n},
$$

untuk $n$ genap, maka maka graf komuting $C(D, X)$ akan membentuk graf tripartisi komplit order $(n+2)$, yaitu $K(1,1, n)$.

\section{Bukti}

a. Karena masing-masing unsur di $X$ saling komutatif, yaitu $r^{i} r^{j}=r^{j} r^{i}$, untuk $i, j=0,1,2, \ldots, n$-1, maka $r^{i}$ dan $r^{j}$ akan 
saling terhubung langsung di $C\left(D_{2 n}, X\right)$. Dengan demikian, maka $C\left(D_{2 n}, X\right)$ akan membentuk graf komplit order $n$.

b. Karena $n$ ganjil, maka unsur $s r^{i}$ hanya komutatif dengan 1 di $D_{2 n}$, untuk $i=0$, $1,2, \ldots, n-1$. Akibatnya $s r^{i}$ hanya terhubung langsung dengan 1 di $C\left(D_{2 n}\right.$, $X)$. Jadi, 1 akan menjadi titik pusat dengan derajat $n$ dan $s r^{i}, i=0,1,2, \ldots$, $n-1$, menjadi titik ujung. Dengan demikian, maka $C\left(D_{2 n}, X\right)$ akan membentuk graf bintang order $(n+1)$.

c. Karena $n$ genap, maka center $D_{2 n}$ adalah $Z\left(D_{2 n}\right)=\left\{1, r^{\frac{n}{2}}\right\}$. Artinya semua unsur di $Z\left(D_{2 n}\right)$ komutatif dengan semua unsur di $D_{2 n}$. Sementara $s r^{i}$ tidak komutatif dengan $s r^{j}$ untuk $i \neq j$. Dengan demikian, maka unsur di $C\left(D_{2 n}, X\right)$ dapat dipartisi menjadi 3 partisi yaitu $\{1\},\left\{r^{\frac{n}{2}}\right\}$, dan $\left\{s, s r, s r^{2}\right.$, $\left.\ldots, s r^{n-1}\right\}$ sehingga masing-masing unsur di dalam satu partisi tidak saling terhubung langsung tetapi unsur di partisi yang berbeda saling terhubung langsung. Jadi, $C\left(D_{2 n}, X\right)$ membentuk graf tripartisi komplit order $(n+2)$.

\section{Teorema 2.}

Misalkan $C\left(D_{2 n}\right)$ adalah graf komuting dari grup dihedral $D_{2 n}(n \geq 3)$. Maka radius dan diameter $C\left(D_{2 n}\right)$ masing-masing adalah

$$
\text { dan } \quad \begin{aligned}
\operatorname{rad}\left(C\left(D_{2 n}\right)\right) & =1 \\
\operatorname{diam}\left(C\left(D_{2 n}\right)\right) & =2 .
\end{aligned}
$$

\section{Bukti}

Diketahui bahwa $1 \circ x=x \circ 1$, untuk semua $x$ $\in D_{2 n}$. Dengan demikian titik 1 akan terhubung langsung dengan semua titik yang lain di $C\left(D_{2 n}\right)$. Dengan demikian, maka $e(1)=1$. Karena radius $C\left(D_{2 n}\right)$ adalah eksentrisitas terkecil di $C\left(D_{2 n}\right)$ maka diperoleh

$$
\operatorname{rad}\left(C\left(D_{2 n}\right)\right)=1 \text {. }
$$

Karena semua titik terhubung langsung dengan 1, maka jarak sebarang dua titik berbeda di $C\left(D_{2 n}\right)$ hanya memuat dengan kemungkinan, yaitu 1 atau 2. Dua titik berbeda akan berjarak
1 jika saling terhubung langsung dan berjarak 2 jika tidak saling terhubung langsung. Karena $s$ dan $r$ tidak komutatif di $D_{2 n}$, maka $d(s, r)=2$. Dengan demikian, maka $e(s)=e(r)=2$. Karena diameter adalah eksentrisitas terbesar maka diperoleh

$$
\operatorname{diam}\left(C\left(D_{2 n}\right)\right)=2 .
$$

\section{Teorema 3.}

Misalkan $C\left(D_{2 n}\right)$ adalah graf komuting dari grup dihedral $D_{2 n}(n \geq 3)$. Maka multiplisitas sikel dari $C\left(D_{2 n}\right)$ adalah $\left[\frac{n^{2}-2 n}{6}\right]$ untuk $n$ ganjil dan $\left[\frac{n^{2}-2 n}{6}\right]+\frac{n}{2}$ untuk $n$ genap.

\section{Bukti}

Untuk $n$ ganjil, sesuai Teorema 1, maka subgraf komplit terbesar di $C\left(D_{2 n}\right)$ adalah $K_{n}$. Dengan demikian maka multiplisitas sikel graf $C\left(D_{2 n}\right)$ sama dengan multiplisitas sikel pada $K_{n}$ yaitu $\left[\frac{n^{2}-2 n}{6}\right]$, untuk $n$ ganjil.

Untuk $n$ genap, sesuai Teorema 1, maka subgraf komplit terbesar di $C\left(D_{2 n}\right)$ adalah $K_{n}$. Dengan demikian maka multiplisitas sikel graf $C\left(D_{2 n}\right)$ sama dengan multiplisitas sikel di $K_{n}$ yaitu $\left[\frac{n^{2}-2 n}{6}\right]+\frac{n}{2}$. Walaupun $r^{\frac{n}{2}}$ komutatif dengan $s r^{i}$ untuk $i=0,1,2, \ldots, n-1$ dan membentuk sikel-3 dengan titik 1 , dalam sikelsikel ini tidak berpengaruh karena sisi $\left(1, r^{\frac{n}{2}}\right)$ sudah terhitung saat menghitung multiplisitas sikel di $K_{n}$. Jadi, multiplisitas sikel di $C\left(D_{2 n}\right)$ tetap sama dengan multiplisitas sikel di $K_{n}$ yaitu $\left[\frac{n^{2}-2 n}{6}\right]+\frac{n}{2}$, untuk $n$ genap.

\section{Teorema 4.}

Misalkan $C\left(D_{2 n}\right)$ adalah graf komuting dari grup dihedral $D_{2 n}(n \geq 3)$. Maka dimensi metrik dari $C\left(D_{2 n}\right)$ adalah $2 n-3$ untuk $n$ ganjil dan $\frac{3 n-4}{2}$ untuk $n$ genap.

\section{Bukti}

Untuk $n$ ganjil, diketahui bahwa $r^{i} r^{j}=r^{j} r^{i}$, untuk $i, j=0,1,2,3, \ldots, n-1$ di $D_{2 n}$. Jadi, $r^{i}$ dan $r^{j}$ saling terhubung langsung di $C\left(D_{2 n}\right)$. Di lain pihak, $s r^{i}$ hanya komutatif dengan 1 di $D_{2 n}$, untuk $i=0,1,2, \ldots, n$-1. Jadi, $s r^{i}$ tidak terhubung langsung dengan $r^{j}$, untuk $i, j=0,1$, $2,3, \ldots, n-1$ di $C\left(D_{2 n}\right)$.

Ambil

$$
S=\left\{s, s r, s r^{2}, \ldots, s r^{n-2}, r, r^{2}, \ldots, r^{n-2}\right\} .
$$


Jadi, $S$ memuat sebanyak $2 n-3$ anggota.

Akan diperoleh bahwa representasi jarak semua titik di $C\left(D_{2 n}\right)$ terhadap $S$ adalah berbeda. Jadi diperoleh dimensi metrik graf $C\left(D_{2 n}\right)$ adalah

$$
\operatorname{dim}\left(C\left(D_{2 n}\right)\right) \leq 2 n-3
$$

Ambil $R$ himpunan bagian dari $V\left(C\left(D_{2 n}\right)\right)$ dengan $|R|=|S|-1<|S|$. Berarti ada minimal satu $s r^{i}, i=0,2,3, \ldots, n-2$ atau $r^{j}, j=$ $1,2,3, \ldots, n-2$ yang tidak masuk di $R$, sebut $s r^{p}$ atau $r^{q}$. Akibatnya, $s r^{p}$ dan $s r^{n-1}$ akan mempunyai representasi jarak yang sama atau $r^{q}$ dengan $r^{n-1}$ akan mempunyai representasi jarak yang sama. Jadi diperoleh dimensi metrik graf $C\left(D_{2 n}\right)$ adalah

$$
\operatorname{dim}\left(C\left(D_{2 n}\right)\right)>2 n-4
$$

atau

$$
\operatorname{dim}\left(C\left(D_{2 n}\right)\right) \geq 2 n-3
$$

Terbukti, $\operatorname{dim}\left(C\left(D_{2 n}\right)\right)=2 n-3$, untuk $n$ ganjil. Untuk $n$ genap, diketahui bahwa $r^{i} r^{j}=r^{j} r^{i}$, untuk $i, j=0,1,2,3, \ldots, n-1$ di $D_{2 n}$. Jadi, $r^{i}$ dan $r^{j}$ saling terhubung langsung di $C\left(D_{2 n}\right)$. Walaupun $r^{\frac{n}{2}}$ komutatif dengan $s r^{i}, i=0,1,2$, $\ldots, n-1$ tetapi $s r^{i}$ tidak komutatif dengan $r^{j}$ untuk $j$ selain $\frac{n}{2}$.

Ambil

$$
S=\left\{s, s r, s r^{2}, \ldots, s r^{\frac{n-2}{2}}, r, r^{2}, \ldots, r^{n-2}\right\} .
$$

Jadi, $S$ memuat sebanyak $\frac{3 n-4}{2}$ anggota.

Akan diperoleh bahwa representasi jarak semua titik di $C\left(D_{2 n}\right)$ terhadap $S$ adalah berbeda. Jadi diperoleh dimensi metrik graf $C\left(D_{2 n}\right)$ adalah

$$
\operatorname{dim}\left(C\left(D_{2 n}\right)\right) \leq \frac{3 n-4}{2}
$$

Ambil $R$ himpunan bagian dari $V\left(C\left(D_{2 n}\right)\right)$ dengan $|R|=|S|-1<|S|$. Berarti ada minimal satu $s r^{i}, i=0,2,3, \ldots, n-2$ atau $r^{j}, j=$ $1,2,3, \ldots, n-2$ yang tidak masuk di $R$, sebut $s r^{p}$ atau $r^{q}$. Akibatnya, $s r^{p}$ dan $s r^{n-1}$ akan mempunyai representasi jarak yang sama atau $r^{q}$ dengan $r^{n-1}$ akan mempunyai representasi jarak yang sama. Jadi diperoleh dimensi metrik graf $C\left(D_{2 n}\right)$ adalah

$$
\operatorname{dim}\left(C\left(D_{2 n}\right)\right)>\frac{3 n-4}{2}-1
$$

atau

$$
\operatorname{dim}\left(C\left(D_{2 n}\right)\right) \geq \frac{3 n-4}{2}
$$

Terbukti, $\operatorname{dim}\left(C\left(D_{2 n}\right)\right)=\frac{3 n-4}{2}$, untuk $n$ genap.

\section{Penutup}

Berdasarkan

pembahasan

dapat

disimpulkan bahwa

a. Radius dan diameter graf komuting dari grup dihedral masing-masing adalah $\operatorname{rad}\left(C\left(D_{2 n}\right)\right)=1$ dan $\operatorname{diam}\left(C\left(D_{2 n}\right)\right)=2$.

b. Multiplisitas sikel graf komuting dari grup dihedral adalah $\left[\frac{n^{2}-2 n}{6}\right]$ untuk $n$ ganjil dan $\left[\frac{n^{2}-2 n}{6}\right]+\frac{n}{2}$ untuk $n$ genap.

c. Dimensi metrik graf komuting dari grup dihedral $D_{2 n}$ adalah $2 n-3$ untuk $n$ ganjil dan $\frac{3 n-4}{2}$ untuk $n$ genap.

Penelitian selanjutnya dapat dilakukan pada graf komuting dari grup simetri atau pada graf non komuting dari grup dihedral dan grup tak komutatif lainnya..

\section{Referensi}

[1] G. Chartrand, L. Lesniak, and P. Zhang, Graphs and digraphs, 6th ed. Florida: Chapman and Hall, 2015.

[2] Abdussakir, N. N. Azizah, and F. F. Novandika, Teori graf. Malang: UIN Malang Press, 2009.

[3] J. Vahidi and A. A. Talebi, "The commuting graphs on groups D2n and Qn," J. Math. Comput. Sci., vol. 1, no. 2, pp. 123-127, 2010.

[4] T. T. Chelvam, K. Selvakumar, and S. Raja, "Commuting graphs on dihedral group main results," J. Math. Comput. Sci., vol. 2, no. 2, pp. 402-406, 2011.

[5] H. Rahayuningtyas, A. Abdussakir, and A. Nashichuddin, "Bilangan kromatik graf commuting dan non commuting grup dihedral," CAUCHY, vol. 4, no. 1, pp. 16-21, 2015.

[6] J. A. Bondy and U. S. R. Murty, Graph theory with applications. New York: Elsevier Science Publishing Co., Inc, 1976.

[7] M. M. A. Ali and S. Panayappan, "Cycle multiplicity of total graph of $\mathrm{Cn}, \mathrm{Pn}$, and K1,n,” Int. J. Eng. Sci. techlogy, vol. 2, no. 2, pp. 54-58, 2010.

[8] C. Hernando, M. Mora, I. M. Pelayo, C. Seara, and D. R. Wood, "Extremal graph theory for metric dimension and diameter," Electron. J. Comb., vol. 17, no. 1, pp. 1-28, 2010.. 